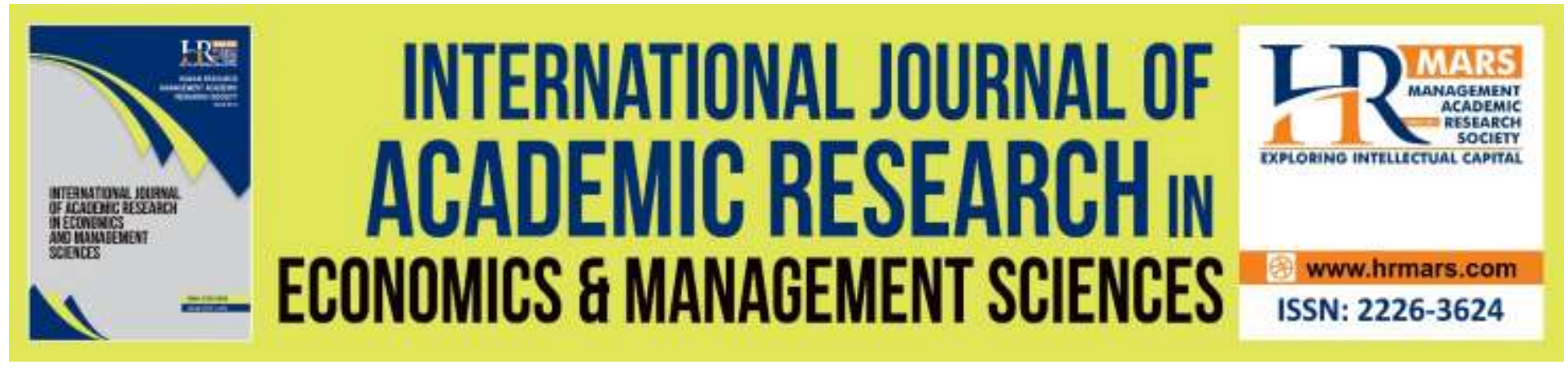

\title{
Socio-Economic Determinants of Routine Immunization Coverage in Dutse, Jigawa State, Northern Nigeria, May 2018
}

Muhammad Abdulkadir, Ruslan Rainis

To Link this Article: http://dx.doi.org/10.6007/IJAREMS/v9-i1/6757

DOI: 10.6007/IJAREMS/v9-i1/6757

Received: 23 November 2019, Revised: 19 December 2019, Accepted: 01 January 2020

Published Online: 27 January 2020

In-Text Citation: (Abdulkadir \& Rainis, 2019)

To Cite this Article: Abdulkadir, M., \& Rainis, R. (2019). Socio-economic Determinants of routine immunization coverage in Dutse, Jigawa State, Northern Nigeria, May 2018. International Journal of Academic Research in Economics and Managment and Sciences, 9(1), 1-17.

\section{Copyright: (C) 2020 The Author(s)}

Published by Human Resource Management Academic Research Society (www.hrmars.com)

This article is published under the Creative Commons Attribution (CC BY 4.0) license. Anyone may reproduce, distribute, translate and create derivative works of this article (for both commercial and non-commercial purposes), subject to full attribution to the original publication and authors. The full terms of this license may be seen at: $\underline{\text { http://creativecommons.org/licences/by/4.0/legalcode }}$

\section{Vol. 9, No. 1, 2019, Pg. 1 - 17}

Full Terms \& Conditions of access and use can be found at http://hrmars.com/index.php/pages/detail/publication-ethics 


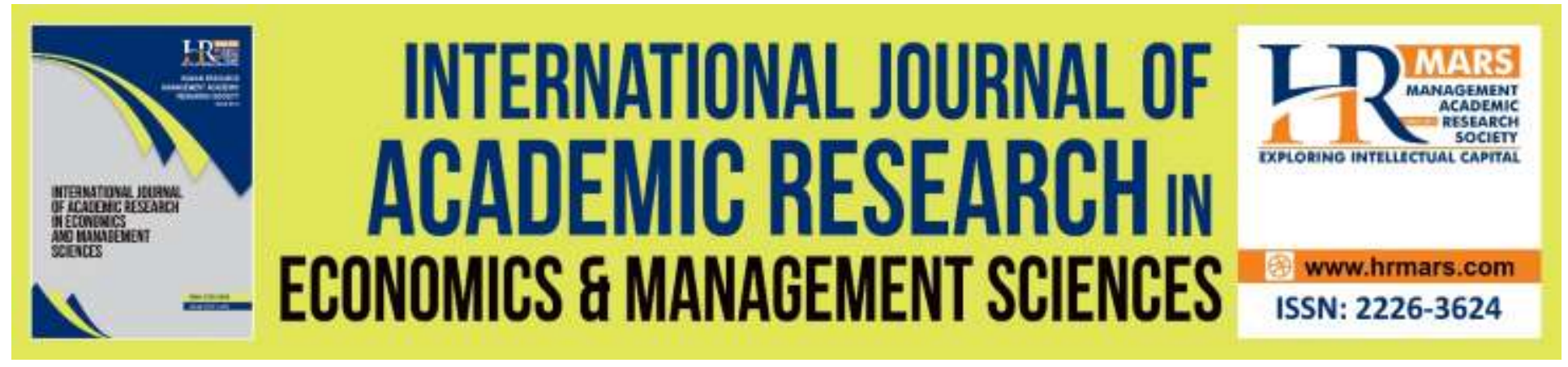

\title{
Socio-Economic Determinants of Routine Immunization Coverage in Dutse, Jigawa State, Northern Nigeria, May 2018
}

\author{
Muhammad Abdulkadir, Ruslan Rainis \\ Geography section, School of Humanities, Universiti Sains Malaysia, School of Preliminary \\ Studies, Sule Lamido University, Kafin Hausa, Jigawa state \\ Email: Mustafaaubali@gmail.com,rruslan@usm.my
}

\begin{abstract}
Immunization is a cost-effective public health intervention to reduce morbidity and mortality associated with infectious diseases. The Nigeria Demographic and Health Survey of 2018 indicated that only $5.4 \%$ of children aged $12-23$ months in Dutse, Jigawa State was fully immunized. The study was conducted to identify the determinants of routine immunization coverage in Dutse area of Jigawa state. The study adopted a cross-sectional method.450 children aged 12-23 months were sampled. Interviews of mothers of these children were carried out using a structured questionnaire to collect data on socio-demographic characteristics, knowledge of immunization, vaccination status of children and reasons for non-vaccination. The study defined a fully immunized child as a child who had received one dose of BCG, three doses of the oral polio vaccine, three doses of Diptheria-Pertussis-Tetanus vaccine and one dose of measles vaccine by 12 months of age. The study performed bivariate analysis and logistic regression using Epi-info software. The findings of the study reveal that the mean age of mothers and children were 27 years (standard error (SE): 0.27 year) and 17 months (SE: 0.8 months) respectively. 79\% of mothers had no formal education while $84 \%$ did not possess satisfactory knowledge of immunization. Only $7.6 \%$ of children were fully immunized. Logistic regression showed that possessing satisfactory knowledge (Adjusted $\mathrm{OR}=18.4,95 \% \mathrm{Cl}=3.6-94.7$ ) and at least secondary education (Adjusted $\mathrm{OR}=3.6,95 \% \mathrm{Cl}=1.2-10.6$ ) were significantly correlated with full immunization. The major determinants of immunization coverage were maternal knowledge and educational status. Raising the level of maternal knowledge and increasing maternal literacy level is essential to improve immunization coverage in this community.
\end{abstract}

Keywords: Dutse, Immunization, Jigawa, Mortality, Routine.

\section{Introduction}

Immunization is a proven tool and a cost-effective public health intervention to reduce morbidity and mortality associated with infectious disease(Omer, 2017). It is one of the key elements of 
primary health care(Anderson et al., 2015). Immunization services are usually delivered via two main strategies namely routine immunization (RI) and supplemental immunization activities (SIAs) (Petrosky et al., 2015). RI is the regular provision of immunization services to successive cohorts of infants through the administration of vaccines (antigens) in a scheduled regimen(Brenzel, Young, \& Walker, 2015). SIAs are mass campaigns targeting all children in a defined age group with the objective of reaching a high proportion of susceptible individuals(Verguet et al., 2015). RI services are usually provided at the fixed post at the health facility and through outreach to remote and hard-to-reach communities(Ducusin et al., 2017). In 1974, the World Health Organization (WHO) launched the Expanded Programme on Immunization (EPI)(Roca et al., 2015). EPI's goals were to ensure that every child received protection against childhood tuberculosis, poliomyelitis, diphtheria, pertussis, tetanus and measles by 1 year of age(Muloiwa, Kagina, Engel, \& Hussey, 2015). In Nigeria, EPI was initiated in 1979(Agboola et al., 2015). The country achieved modest progress in immunization coverage during 1980 -1990(Mpabalwani, Mwenda, Tate, \& Parashar, 2017). However, the 1990s witnessed a major decline in RI coverage mainly due to the collapse of the Primary Health Care system, poor funding by governments and lack of political commitment and ownership. In 1996, Nigeria's EPI program was revitalized with renewed government ownership and oversight. Although this led to an increase in immunization coverage, immunization surveys conducted in the country in 2003 and 2006 indicated that the coverage for all the antigens was still below 50\%(Adeloye et al., 2017).

Of the six geo-political zones in Nigeria, the north-west zone has the worst RI coverage in the country(Eboreime, Abimbola, \& Bozzani, 2015). The low RI coverage in this zone has been a major factor for the continuous transmission of wild poliovirus and circulating vaccine-derived poliovirus (cVDPV) in Nigeria(Eboreime et al., 2015). Among the seven states in north-west Nigeria, Jigawa State has one of the poorest immunization coverage - in 2018, the state recorded a Diptheria-Pertussis-Tetanus (DPT) 3 vaccine coverage of $8.8 \%$, Oral Polio Vaccine (OPV) 3 of $22.8 \%$ and measles vaccine coverage of $14.1 \%$ (Gunnala et al., 2016).

Nigeria has witnessed a gradual but consistent reduction in immunization coverage. By 1996, the national data showed less than $30 \%$ coverage for all antigens, and this decreased to $12.9 \%$ in 2003(Odusanya, Alufohai, Meurice, \& Ahonkhai, 2008). This figure which is consistent with the 2003 national immunization coverage survey figures is among the lowest in the world and explains the poor health status of children in the country. It is the worst in the West African subregion, only better than Sierra Leone. For instance, the polio epidemic in Nigeria is the worst in the African region and constitutes a threat to other nations(Adebayo, Oladokun, \& Akinbami, 2012)

immunization and vaccination are two of the most important public health interventions and constitute a cost-effective strategy to reduce both the morbidity and mortality associated with infectious diseases.

Over two million deaths are delayed through immunization each year worldwide(Itimi, Dienye, \& Ordinioha, 2012). Despite this fact, vaccine-preventable diseases remain the most common cause of childhood mortality with an estimated three million deaths each year(Jenkins et al., 2008). In recent times, vaccination has had a major impact on measles deaths. From 2000 to 2005, more than 360 million children globally received measles vaccine through supplementary 
immunization activities. Moreover, improvements have been made in routine immunization over this period.

These accelerated activities have resulted in a significant reduction in estimated global measles deaths. Overall, global measles mortality decreased by $60 \%$ between 1999 and 2005 . The largest gains occurred in Africa where measles cases and deaths decreased by nearly $75 \%$ (Jenkins et al., 2008). Thus, there is a lot of pressure on health facilities in different countries in controlling the disease through vaccination. Indeed, measles is targeted by the WHO in its expanded program of immunization (EPI).

In their study, Henry et al. (Fatiregun \& Okoro, 2012) showed only immunizations completed for children aged 12-23 months, the usual age group for reporting immunization rates. Their results revealed that one-fourth of all children aged 12-23 months had received the three recommended doses of polio but many missed the corresponding third dose of DPT3, which was received by only $5.1 \%$ of one-year-olds. Only $2.2 \%$ of children $12-23$ months of age received all recommended doses. More children in Yobe (3.8\%) than in Katsina (2.5\%) and Zamfara (0.2\%) received all recommended doses $(p=0.05)$. Further analysis of the data shows that $67 \%$ of parents who were unable to receive all immunizations reported a lack of vaccine as a problem, and $13 \%$ had difficulties with the long wait. Children in urban areas have consistently higher immunization rates than those in rural areas. Overall, $4.6 \%$ of children 12-23 months of age had received all of the recommended doses by one year of age, compared to only $1.1 \%$ in the rural areas $(p=0.005)$.

Like many other sub-Sahara African countries, Nigeria is still experiencing tremendous crises in maternal and child health care. These crises reflect more on under-five morbidity and mortality, which has not witnessed a significant improvement from its level since the 1990s. For instance, in 1990, the under-five mortality rate was 147 deaths per 1000 births, while in 1995 it increased to 176 deaths per 1000 births, and in 2000 it was 153 deaths per 1000 births. According to the latest Nigerian demographic and health survey 2018, out of every 1000 children born in Nigeria, 70.49 died before reaching five years of age, with female and male infant mortality estimated at 67.34 and 73.55 deaths/1000 live births respectively. In recognition of the risks faced by Nigerian children, one of the important services covered by PHC in Nigeria is immunization. Although immunization began in Nigeria in 1956 when smallpox was severe nationwide the national immunization tagged Expanded Program on Immunization started in 1979 to combat deadly childhood diseases, which were regarded as the cause of high infant morbidity and mortality in Nigeria. These diseases are polio, measles, yellow fever, whooping cough, diphtheria, tuberculosis of and marasmus(Angela, Babatunde, Akinwumi, \& Edet, 2012). Although malaria is not included in the list of childhood diseases, researches are ongoing to develop a malaria vaccine that will hitherto prevent and reduce infant malaria. Recently, a purified irradiated PFSPZ vaccine administered to individuals by inoculation in the skin proved safe, suboptimally immunogenic and protective. Also, efforts are on towards an effective vaccination to combat influenza. In a recent report, changing the amino acid residue in the stem cell region of the HA2 subunit of the haemagglutinin molecule showed promise as a strategy for cell culture-based influenza vaccines

The vision of EPI in Nigeria is to improve the health of Nigerian children by eradicating all the six killer diseases, which are polio, measles, diphtheria, whooping cough, tuberculosis, and yellow fever. Between 1985 and 1990, as outlined in the national health plan for that period, the 
objectives of EPI were to strengthen immunization, accelerate disease control and introduce new vaccines, relevant technologies, and tools. In1995 in line with the above, Nigeria became a signatory to the World Health Assembly, adopted the World Health Assembly Resolution (WHAR) and United Nations General Assembly Special Session (UNGASS) goals for all countries to achieve by 2005 (i) polio eradication, (ii) measles mortality reduction and (iii) maternal and neonatal tetanus elimination (MNTE). Nigeria also adopted the millennium development goals (MDGs) calling for a two-thirds reduction in child mortality, as compared to 1990, the year 2005. In addition to the above, the country ratified the United Nations General Assembly Special Session (UNGASS) goals urging Nigeria to achieve by 2010 (i) ensure full immunization of children under one year of age at $90 \%$ coverage nationally with at least $80 \%$ coverage in every district or equivalent administrative unit, and (ii) vitamin A deficiency elimination. In 1998 following from the above, Nigeria laid out the core activities of EPI policies which included the following: (i) monitoring of the performance, quality and safety of the immunization system through indicators; (ii) assessment of the current burden of vaccine-preventable diseases as well as the "future" burden of vaccine-preventable diseases in terms of sickness, death and disability, as well as the economic burden; (iii) assessment of the impact of vaccination strategies, through ongoing epidemiological surveillance and reliable laboratory confirmation, as well as impact assessments in Nigeria; (iv) monitoring of the national immunization policies, particularly the vaccines used in the country and the target population for these vaccines (immunization schedules); and (v) monitoring of the overall proportion of children and women who are vaccinated (immunization coverage) and ensuring that all districts of the country are well covered with vaccination. In 2000, following the African Regional Summit on EPI held in Harare in November 1999, the Federal Ministry of Health specifically stated its policies on the country's initial visions for EPI as follows:

(i) Immunization System Strengthening: By the year 2004, Nigeria should achieve the EPI districtfocused plan and attain 80\% DPT3 coverage in all the states of the federation. The specific policy also stated that the government should ensure increased funding for EPI. (ii) Accelerated Disease Control: By the year 2004, there should be no cases of acute flaccid paralysis associated with wild poliovirus in Nigeria. As for measles, by the year 2004, the country should have reduced measles morbidity by $90 \%$ and measles mortality by $95 \%$; while the coverage for yellow fever is expected to increase to at least $80 \%$. (iii) Innovations: By the year 2004, Nigeria should include vitamin A and hepatitis B (HB) in its national immunization programs; and the vaccination coverage should not be less than $80 \%$ as with other antigens. Under the new technology-driven, the country should adopt the multi-dose vial policy (MDVP) and vaccine vial monitor (VVM) and also introduce new methods for monitoring its use.

Immunization against childhood diseases such as diphtheria, pertussis, tetanus, polio, and measles is one of the most important means of preventing childhood morbidity and mortality. Achieving and maintaining high levels of immunization coverage must,, therefore, be a priority for all health systems. In order to monitor progress in achieving this objective, immunization coverage data can serve as an indicator of a health system's capacity to deliver essential services to the most vulnerable segment of a population.

Dutse represents a typical rural community in Jigawa State and the coverage for RI antigens in this community is below the $80 \%$ average required for herdimmunity against vaccine- 
preventable diseases (VPDs)(Eboreime et al., 2015). The administrative coverage for OPV3 and DPT3 in Dutse were $22 \%$ and 54\% respectively in 2006, and 35\% and 59\% for OPV3 and DPT3 respectively in 2017(Touray et al., 2016). A nation-wide demographic and health survey conducted in 2018 indicated that only $5.4 \%$ of children aged $12-23$ months in this community were fully immunized(Abubakar, 2018). Based on this, this study was conducted to assess the knowledge of mothers (caregivers) on RI, determine the coverage for RI antigens and identify the determinants of full immunization to guide evidenced-based interventions to improve immunization coverage in the community.

\section{Methods}

\section{Description of Study area}

Dutse Local Government Area is in the Jigawa State of Nigeria. It is located between latitudes $11^{\circ}$ $45^{\prime} 22.25^{\prime \prime} \mathrm{N}$ and between longitudes $9^{\circ} 20^{\prime} 20.26 " \mathrm{E}$. The local government area is bounded in the North by Ringim L.G.A, in the South by Birnin Kudu L.G.A, East by Kiyawa L.G.A all in Jigawa state and in the west by Kano state(Figure 1) (Idi, 2017). The Dutse town serves as both the state capital and the headquarters of the Local Government Area. The major languages spoken in the local government area are Hausa, Fulfude and Banawa. The local government area is made of the following towns Ruru, Dundubus, Karnaya, Dutse, Chamo, Sakwaya, Jaudi, Madobi, and Kudai and villages such as Chaichai, Yargaba, Dagwaje, Wurma, Warwade, Yalwa, Hammayayi and Baranda. Some of the crops grown in the L.G.A are maize, millets, beans, sorghum, rice, groundnuts, cotton, sesame, and the tree crops are Date palm, cashew, citrus, mangoes and Guava (JARDA). Lastly, the NIFOR, Date palm substation is cited in Dutse town.

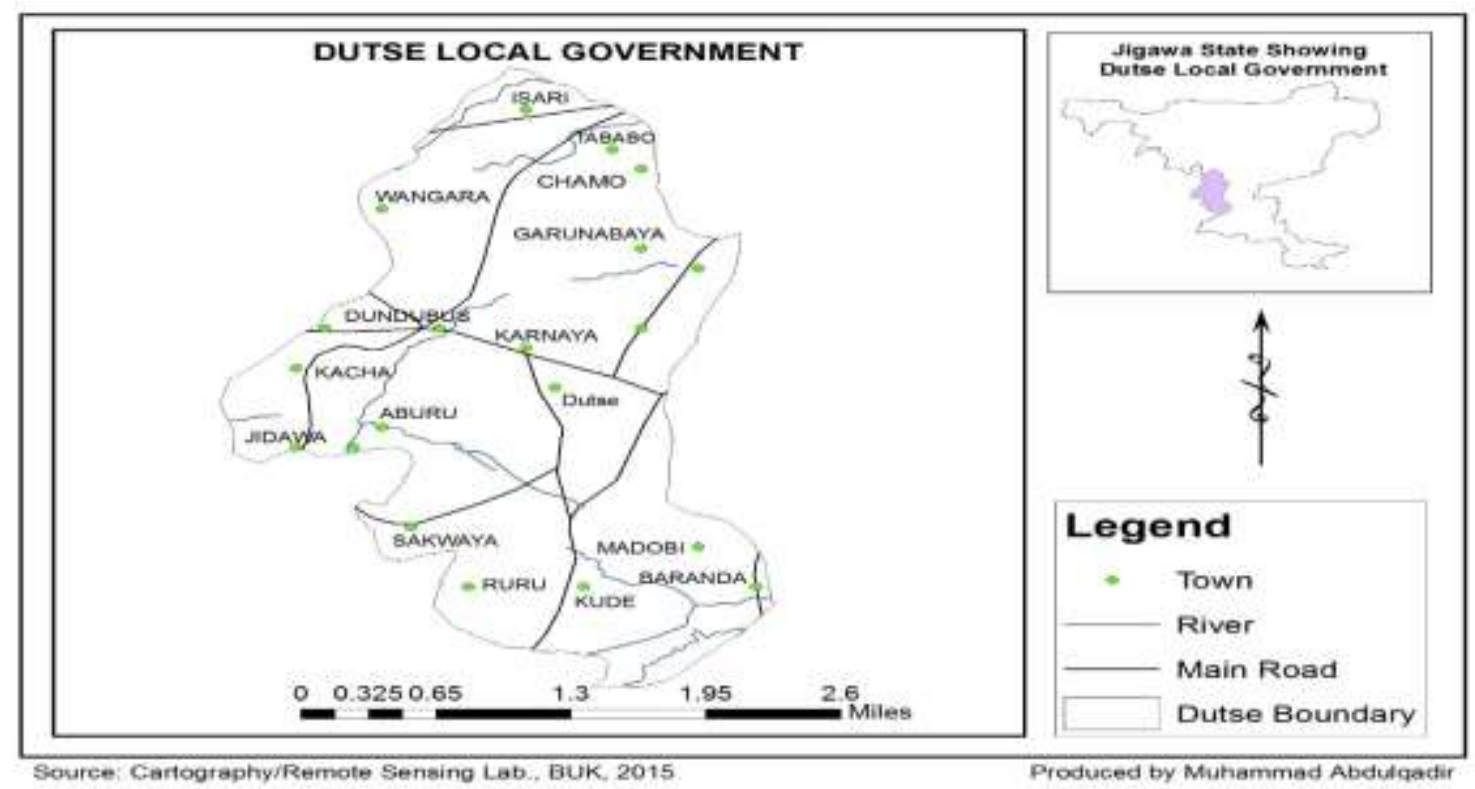

Figure1: Map of the Study area

The community (Dutse) has an estimated population of 69, 906 people projected from the 2006 National population census. The majority of the inhabitants are Hausas and are predominantly farmers. RI services in the community are delivered by six primaries and two secondary health facilities (all government-owned), and through immunization outreach services(Yahaya \& 
Dogara, 2018). The community is divided into three districts and each district has four villages. Altogether, there are 47 settlements in the community; each settlement consists of several households. For the purpose of this study, each settlement constituted a cluster.

\section{Study Design}

A community-based cross-sectional study was conducted for this study. The respondents were mothers or caregivers of sampled children. For a child to be eligible for sampling, he or she must have been between 12- 23 months old at the time of the study.

Sample size determination: The study determined the number of children to be sampled using the methods recommended by the World Health Organization (WHO) for Immunization Coverage Cluster Survey (13). The calculation of the sample size was based on a hypothesized full immunization coverage of $5.4 \%$ (9), a significance level of $5 \%$ - corresponding to a standard normal deviate $(\mathrm{z})$ of 1.96, power of $80 \%$, precision (d) of $3 \%$ and design effect (DEFF) of 2.

The study used the formula: $n=\{(z 2 p q / d 2) \times D E F F\}$ and obtained a minimum sample size of 436 children. However, we sampled an equal number of children from each of 30 clusters; thus, 15 children were sampled per cluster giving a total sample size of 450 children.

Sampling Method: The study employed a two-stage cluster sampling technique to sample eligible children. A random number using tables of random numbers was used. The selected random number was 1359; - To determine the village in which cluster one was located, we identified the first village listed in which the cumulative population equals or exceeds the random number (1359). To determine the village where cluster two was located, we added the sampling interval to the random number $(2330+1359=3689)$ and identified the village whose cumulative population contained this number (3689). To identify the villages where subsequent clusters (clusters three to thirty) were located, we kept on adding the sampling interval to the "preceding sum (running total) of the sampling interval and random number" and locating the village whose cumulative population contained this number (Table 1).

Table 1: Study cluster in different villages in Dutse

\begin{tabular}{cccc}
\hline Villages & Population & Cumulative population & Cluster Number \\
\hline Ruru & 3500 & 3500 & 1 \\
Dundubus & 7480 & 10980 & $2,3,4,5$ \\
Dutse & 7601 & 18851 & $6,7,8$ \\
Madobi & 5800 & 24381 & $9,10,11$ \\
Jaudi & 4132 & 28513 & 12.13 \\
Chaichai & 4300 & 32813 & 14,15 \\
Yargaba & 2851 & 35664 & 16 \\
Hammayayi & 4117 & 39781 & 17,18 \\
Baranda & 7060 & 46841 & $19,20,21$ \\
Sakwaya & 6800 & 58206 & 24,25 \\
Chamo & 11700 & 69906 & $26,27,28,29,30$ \\
\hline
\end{tabular}

Selection of households: At stage two, selected 15 households from each of the 30 clusters selected at stage one. The first household in each cluster was selected randomly using the table of random numbers. Subsequent households were selected contiguously in the right direction 
until the number of households for that cluster was completed. From each selected household, one eligible child was selected. If a selected household had more than one eligible child, only one was randomly selected. If a selected household had no eligible child, the next contiguous household was visited and one eligible child selected.

Respondents knowledge grading: To assess the knowledge of mothers, their responses scored to five questions on various aspects of RI and VPDs. Each correct response was scored one point while each wrong response was scored zero. Mothers, who scored below two points, were graded as having poor knowledge while those who scored three points and above were graded as having satisfactory knowledge. To reduce the possibility of guessing by the mothers, we asked only open-ended questions to assess the level of knowledge.

Routine Immunization antigens Validity: For any antigen administered to a child to be considered valid, that antigen must have been administered at the recommended age; and for multiple-dose antigens, not less than 4 weeks interval between the doses. We considered a child's BCG vaccine valid if a scar was present irrespective of whether the vaccination was recorded on the card or obtained by history. BCG vaccination recorded on the card but without a scar was also considered valid.

Vaccination status of children: Based on the type and doses of valid RI antigens received, we categorized the children as fully immunized, partially immunized, or un-immunized. We defined these categories of vaccination status as follows: - Fully immunized child: a child who had received one dose of BCG, three doses of OPV (excluding OPV given at birth), three doses of DPT vaccine and one dose of measles vaccine by 12 months of age; - Partially immunized child: a child who missed at least any one of the above doses; - Un-immunized child: a child who had not received any vaccine by 12 months of age.

Data processing and analysis: The study reviewed all completed questionnaires prior to electronic data entry. Double data entry was performed to minimize errors. Univariate analysis was conducted in order to obtain frequency and proportions, and bivariate analysis to identify factors that determine full immunization status. The study used the chi-square test to determine statistical significance; a p-value of less than 0.05 was considered statistically significant. A logistic regression model was created for factors that were significant at bivariate analysis. Data analysis was performed using Epi-info software version 3.5.1.

Ethical considerations: Ethical clearance for this study was obtained from the ethical committee of the Jigawa State Ministry of Health, Dutse. Informed consent was obtained from each respondent. The confidentiality of the respondents was assured and maintained during and after the study.

\section{Results}

\section{Socio-demographic characteristics of mothers and children}

The mean age of the mothers was 27 years (standard error $(\mathrm{SE})=0.27$ years). The age ranged from 15 to 44 years. Thirty-one percent of mothers were between 20 to 24 years old. All the mothers (100\%) practiced Islam, $79 \%$ had no formal education, $81 \%$ were traders, and $98 \%$ were married. The mean age of the children was 17 months (SE=0.8 month); the age ranged from 12 to 23 months. Fifty-two percent of the children were males (Table 2). 
Table 2: Socio-demographic characteristic of Respondent

\begin{tabular}{ccc}
\hline Age & Number of Respondents & Percentage (\%) \\
\hline $15-19$ & 17 & 3.8 \\
$20-24$ & 138 & 30.7 \\
$24-29$ & 122 & 27.1 \\
$30-34$ & 109 & 24.2 \\
$35-39$ & 45 & 10.0 \\
$40-44$ & 19 & 4.2 \\
Religion & & \\
Islam & 450 & 100 \\
Educational status & & \\
None & 355 & 78.9 \\
Primary & 50 & 11.1 \\
Secondary & 35 & 7.8 \\
Tertiary & 10 & 2.2 \\
Occupation & & \\
Trader & 363 & 80.7 \\
Housewife & 64 & 14.2 \\
Tailor & 9 & 2.0 \\
Teacher & 8 & 1.8 \\
Health worker & 4 & 0.9 \\
Civil servant & 2 & 0.4 \\
Marital status & & \\
Married & 441 & 98.0 \\
Divorced & 5 & 0.9 \\
Widow & 4 &
\end{tabular}

\section{Knowledge and attitudes on RI and VPD}

Forty-four percent(44\%) of the mothers knew the correct purpose of childhood immunization, $20 \%$ knew the timing of first RI visit, $14 \%$ knew the timing of the second visit while $16 \%$ knew the timing of the last visit; only $12 \%$ knew the correct number of visits to health facility to complete RI. Sixty-one percent (61\%) mentioned measles while $50 \%$ mentioned poliomyelitis as VPDs. Malaria and diarrhea diseases were also mentioned as VPDs by $12 \%$ and $6 \%$ of mothers respectively. The commonest symptoms of VPDs recalled by the mothers were fever (57\%), followed by cough (48\%), skin rash (34\%) and paralysis (19\%). Seventy-nine percent of the mothers believed that immunization is beneficial to children, $81 \%$ believed that immunization is safe, while $66 \%$ believed that immunization is very effective in preventing VPDs in children. However, $14 \%$ of mothers believed that immunization can cause infertility later in the life of children, while $63 \%$ believed that immunization prevents all childhood diseases.

\section{Grading of Knowledge}

Forty-three percent (43\%) of mothers had a knowledge score of zero, $28 \%$ scored one point while $12 \%$ scored 2 points. Five percent of mothers had a score of 3 points; another $5 \%$ scored 4 points while $7 \%$ scored 5 points. Based on the scores, $84 \%$ possessed poor knowledge (score of 0 - 2 
INTERNATIONAL JOURNAL OF ACADEMIC RESEARCH ECONOMICS AND MANAGEMENT SCIENCES

Vol. 9, No. 1, 2019, E-ISSN: 2226-3624 ㄷ 2019 HRMARS

points) while $16 \%$ possessed satisfactory knowledge (score of 3 - 5 points). High education level was significantly associated with satisfactory knowledge $-46 \%$ of mothers whose knowledge was satisfactorily possessed high education level (secondary/post-secondary) ( $p$-value: $<0.05$ ).

\section{Coverage for RI antigens}

The coverage for all RI antigens obtained by both maternal history and immunization cards is shown in Table 3.

Table 3: Immunization coverage in Dutse, Jigawa State

\begin{tabular}{ccc}
\hline Routine Immunization Antigens & $\begin{array}{c}\text { Maternal History } \\
\text { Coverage }\end{array}$ & $\begin{array}{c}\text { Coverage by immunization } \\
\text { card }\end{array}$ \\
\hline Antigens Administration at birth & $80(17.8)$ & $40(8.9)$ \\
BCG & $89(19.8)$ & $41(9.1)$ \\
OPV0 & $84(18.7)$ & $41(9.1)$ \\
HBV1 & & \\
Antigens Administration at 6 & & $38(8.4)$ \\
weeks & $73(16.2)$ & $41(9.1)$ \\
OPV2 & $76(16.9)$ & $38(8.4)$ \\
DPT1 & $66(14.7)$ & \\
HBV2 & & $33(7.3)$ \\
weeks & & $35(7.8)$ \\
OPV2 & $55(12.2)$ & \\
DPT2 & $60(13.3)$ & \\
Antigens Administration at 10 & & $26(5.8)$ \\
weeks & & $27(6.0)$ \\
OPV3 & $41(9.1)$ & $28(6.2)$ \\
DPVT3 & $43(9.6)$ & \\
HBV3 & $44(9.8)$ & $24(5.3)$ \\
Antigens Administration at 14 & & $22(4.9)$ \\
months & & \\
Measles & & \\
Yellow fever & $35(15.1)$ & \\
Antigens Administration at 9 & $35.8)$ & \\
& & \\
& & \\
\hline
\end{tabular}

For all antigens, coverage obtained by maternal history was higher than coverage obtained by immunization card. The proportion of children vaccinated with OPV 0 (19.8\%), HBV 1 (18.7\%) and BCG (17.8\%) - all given at birth, were more than the proportion of children vaccinated with antigens given at other times. According to maternal history, $7.6 \%$ of the children had been fully immunized, $18.9 \%$ were partially immunized, while $73.6 \%$ were un-immunized. However, according to the immunization cards, $4.7 \%$ of the children had been fully immunized while $4.9 \%$ were partially immunized. 
INTERNATIONAL JOURNAL OF ACADEMIC RESEARCH ECONOMICS AND MANAGEMENT SCIENCES

Vol. 9, No. 1, 2019, E-ISSN: 2226-3624 @ 2019 HRMARS

\section{Reasons for non-vaccination}

The reasons given by the mothers for the non-vaccination of their children are shown in Figure 1.

Sixty-six percent of mothers who had never vaccinated their children gave reasons relating to lack of knowledge on RI for non-vaccination of their children, 37\% gave reasons relating to lack of permission from the husband. Nine percent gave no reason for non-vaccination of their children.

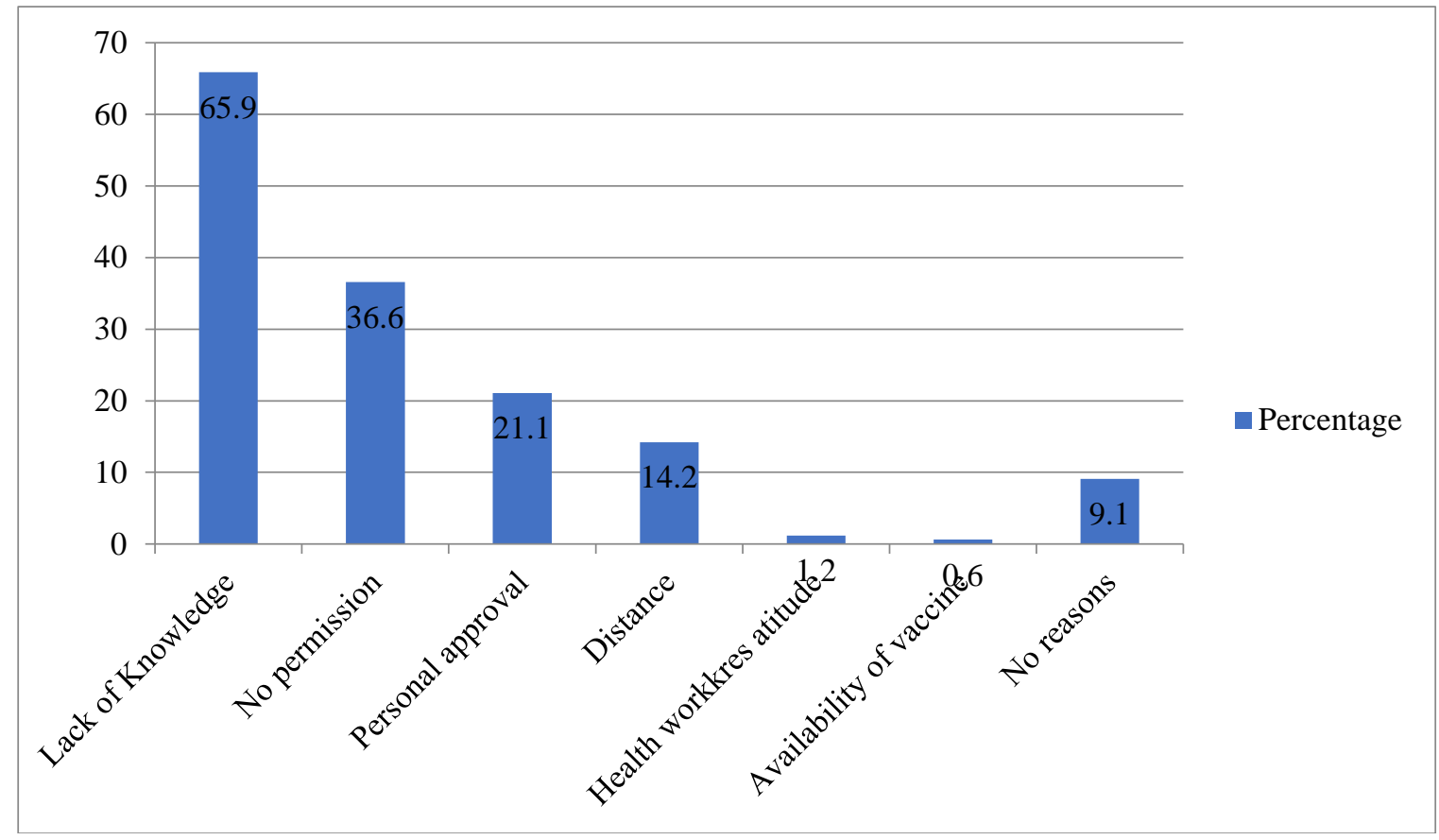

Figure 1: Reasons for not Vaccination

\section{Determinants of full immunization}

Five factors were significantly associated with full immunization at bivariate analysis: possessing a satisfactory level of knowledge on RI, possessing at least secondary education, receiving antenatal care, having received information on $\mathrm{RI}$ in the 12 months preceding the study, and delivery at a health facility (Table 4). Of these factors, possessing a satisfactory level of knowledge on RI ( $p$-value: $<0.05)$ and possessing at least secondary education ( $p$-value: $<0.05$ ) remained as the only independent determinants of full immunization after performing logistic regression (Table 5). 
Table 4: Bivariate analysis of factors associated with immunization

\begin{tabular}{cccc}
\hline Factors & Partially/unimmunized & Fully immunized & $\mathrm{X}^{2}$ \\
\hline Educational level & $392(94.2)$ & $13(38.2)$ & \\
None/primary & $24(5.8)$ & $21(61.8)$ & 103.4 \\
$\begin{array}{c}\text { Secondary/tertiary } \\
\text { Knowledge grade }\end{array}$ & $374(89.9)$ & $2(5.9)$ & \\
Poor & $42(10.1)$ & $32(94.1)$ & 155.4 \\
Satisfactory & $324(77.9)$ & & \\
Received ANC & $92(22.1)$ & $34(100.0)$ & \\
No & & & \\
Yes & $111(85.1)$ & $1(2.9)$ & \\
No & $305(73.3)$ & $33(97.1)$ & \\
Yes & & & \\
Received RI Information & $354(85.1)$ & $4(11.8)$ & 99.5 \\
Place of delivery & $62(14.9)$ & $30(88.2)$ & \\
Home & & & \\
Hospital & & &
\end{tabular}

Table 5: Logistic Regression Analysis of factors with full immunization

\begin{tabular}{cccccc}
\hline Factors & Odd ratio & $95 \%$ C.I & Coefficient & S.E & P-value \\
\hline $\begin{array}{c}\text { Educational } \\
\text { status }\end{array}$ & 3.63 & $1.24-10.57$ & 1.29 & 0.55 & 0.0183 \\
Knowledge & 18.39 & $3.57-94.70$ & 2.91 & 0.84 & 0.0005 \\
Place of delivery & 2.70 & $0.73-10.00$ & 0.99 & 0.67 & 0.1374 \\
Access to RI & 0.51 & $0.03-8.72$ & -0.67 & 1.44 & 0.6443 \\
ANC attendance & 1.75 & $0.00-1.02$ & 12.6324 & 1.53 & 0.9038 \\
\hline
\end{tabular}

\section{Discussion of Results}

The study found that the majority of mothers in our study in a rural community in Jigawa State possessed poor knowledge of RI and VPDs. High education level was found to be significantly associated with satisfactory knowledge. Although the attitude of mothers towards immunization was generally positive, some believed that immunization can cause infertility in children. The finding of this study revealed very low coverage for all RI antigens. Less than $10 \%$ of the children were fully immunized(Liso, Massenzio, \& Stracci, 2017). Almost three out of every four mothers had never vaccinated their children(Habib et al., 2017). The study found that possessing satisfactory knowledge on $\mathrm{RI}$ and possessing high education level were the independent determinants of full immunization in these communities.

The majority of mothers in this study community possessed poor knowledge of RI, similar to findings obtained in North India (Paul \& Sahoo, 2015). The poor knowledge of mothers in this study may be partly, attributed to the low level of education in these communities. The study established that mothers with low educational level were less knowledgeable on RI compared to those with a high educational level. Education has been described as the root of knowledge. It is expected that mothers with high education levels ought to understand scientific information more easily than those with a low educational level. This finding is consistent with that obtained 
in Edo, Southern Nigeria and Istanbul, Turkey(Abhulimhen-Iyoha \& Ibadin, 2015; Carrasco et al., 2015).

Measles and poliomyelitis were the most common VPDs recalled by mothers in our study, similar to findings obtained in some states in Nigeria(Saleh, 2016). Both diseases(Measles and poliomyelitis) are on the center stage of both national and global public health activities, while measles is targeted for elimination in Nigeria, poliomyelitis is targeted for global eradication(Fowotade et al., 2015). Most mothers especially, in northern Nigeria are familiar with the characteristic maculopapular rash associated with measles infection(Faneye, Adeniji, Olusola, Motayo, \& Akintunde, 2015). In addition, the repeated polio SIAs in Nigeria has popularized poliomyelitis especially in rural communities in northern Nigeria.

Fourteen percent of mothers in our study community believed that immunization can cause infertility in children. This finding readily brings to mind the event that led to the suspension of immunization activities in Northern Nigeria between 2003 and 2005. During this period, OPV was erroneously perceived to possess anti-fertility constituents(Iduseri \& Osemwenkhae, 2016). The widespread misconception resulted in poor acceptability and outright suspension of immunization activities in several northern states, perhaps due to the decision of parents to defy purported plots of the western world to reduce Nigeria's population. This period witnessed a major set-back for immunization activities in Nigeria as both RI and SIAs dipped profoundly. This study provides a rationale to scale up public enlightenment and social mobilization activities and engagement of religious, traditional and political leaders to correct this misconception.

The coverage obtained for all antigens in this study was lower than that reported by several other researchers(Abad et al., 2015). The proportion of children found to be fully immunized in our study was lower than the findings in Edo, Southern Nigeria, Brazil and Turkey(Andrade et al., 2017). However, it is comparable to the figure obtained by NDHS 2018(Nakayiza, 2018). The 9.1\% OPV3 coverage obtained in this study has a great implication for the global polio eradication initiative; this OPV3 coverage is far below the $80 \%$ recommended by the WHO for polio eradication (Ongwae et al., 2017), and creates a substantial population gap - a key risk factor for the emergence and circulation of cVDPV(Adekanle, Ndububa, Olowookere, ljarotimi, \& ljadunola, 2015). Similarly, the $15.1 \%$ coverage we obtained for the measles vaccine is lower than the $90 \%$ recommended by the WHO/ UNICEF strategic plan for measles morbidity and mortality reduction(Gibson et al., 2015)

In a study in India, found that there is satisfactory maternal knowledge on RI is an independent determinant of full immunization in this community(Healy, Rench, Montesinos, Ng, \& Swaim, 2015). This finding is consistent with those of other studies. As expected, knowledge regarding the benefit and schedule of $\mathrm{Rl}$ is a powerful tool that positively influences a mother's decision to fully immunize her child. However, the educational level, which was found to be significantly associated with knowledge, is very low in this community. This correlates with the finding of this study which shows that only $7.6 \%$ of mothers had fully immunized their children. Furthermore, findings from our study indicated that high education level was an independent determinant of full immunization similar to findings obtained in Edo State, Southern Nigeria and Turkey(Carrasco et al., 2015).

However, a study conducted in an urban area of Brazil demonstrated that maternal literacy was not associated with full immunization(Healy et al., 2015). This contrasting finding in Brazil may 
possibly, be due to the urban setting of the study area and the recruitment of study participants from the health facilities rather than the community. The independent effect of high education level on full immunization demonstrated by this study highlights the need for inter-sectoral collaboration between the health and education sectors to improve immunization coverage in these communities.

The interpretation and generalization of the findings from this study are subject to three limitations. Firstly, the study did not explore factors related to immunization service delivery including vaccine availability, health care personnel and logistics. Secondly, the study could not verify the information provided by the respondents regarding the antigens received by their children. The researcher tried their best to describe the site, dose and timing of the antigens to obtain accurate information. Finally, the study was limited in geographical scope. Although our study community is a good prototype of rural communities in northern Nigeria, the researchers acknowledged that conducting this study in the entire Jigawa State or Northern Nigeria could have produced different results. However, the study used an absolute precision of $3 \%$ instead of $5 \%-10 \%$ to achieve a sufficiently large sample size to increase the precision and allows for generalization of the findings, at least in Jigawa State.

\section{Conclusion}

In conclusion, the maternal knowledge and literacy level in this community is very low. Uptake of RI antigens was also, generally very low. Poor maternal knowledge and low level of education independently, determine full childhood immunization in the community. The community, supported by the State Ministry of Health and the State Ministry of Information should embark on focused public enlightenment and health education activities on the benefits, schedule, and doses of $\mathrm{Rl}$, targeting both mothers and fathers to improve the level of knowledge and correct misconceptions regarding some aspects of RI. Inter-sectoral collaborations between the health and education sector should be strengthened. In this light, the State Ministry of Education and other relevant partner agencies should support the organization of flexible adult education classes as well as the enrolment of the girl child into primary and secondary school.

\section{References}

Abad, R., Biolchi, A., Moschioni, M., Giuliani, M., Pizza, M., \& Vázquez, J. (2015). A large portion of meningococcal antigen typing system-negative meningococcal strains from spain is killed by sera from adolescents and infants immunized with 4CMenB. Clin. Vaccine Immunol., 22(4), 357-360.

Abhulimhen-lyoha, B. I., \& Ibadin, M. O. (2015). Cord care education and its content given to mothers at antenatal clinics in various health facilities in Edo state, Nigeria. Sahel Medical Journal, 18(3), 129.

Abubakar, I. R. (2018). Exploring the determinants of open defecation in Nigeria using demographic and health survey data. Science of the total environment, 637, 1455-1465.

Adekanle, O., Ndububa, D. A., Olowookere, S. A., ljarotimi, O., \& Ijadunola, K. T. (2015). Knowledge of hepatitis $B$ virus infection, immunization with hepatitis $B$ vaccine, risk perception, and challenges to control hepatitis among hospital workers in a Nigerian tertiary hospital. Hepatitis research and treatment, 2015. 
Adeloye, D., Jacobs, W., Amuta, A. O., Ogundipe, O., Mosaku, O., Gadanya, M. A., \& Oni, G. (2017). Coverage and determinants of childhood immunization in Nigeria: a systematic review and meta-analysis. Vaccine, 35(22), 2871-2881.

Agboola, S. M., Busari, O. A., Segun-Agboola, B. T., Olajide, T. J., Shabi, O. M., \& Elegbede, O. T. (2015). Knowledge, attitude, perceptions of adult males towards childhood immunizations in southwest Nigeria. American Journal of Health Research, 3(1), 1-5.

Anderson, N., Wilson, N., Moon, T., Kanem, N., Diop, A., \& Gbodossou, E. (2015). Redefining Immunization: Not Just a Shot in the Arm. Global Health Communication, 1(1), 1-9.

Andrade, A. L., Minamisava, R., Tomich, L. M., Lemos, A. P., Gorla, M. C., de Cunto Brandileone, M. C., ... Bierrenbach, A. L. (2017). Impact of meningococcal C conjugate vaccination four years after introduction of routine childhood immunization in Brazil. Vaccine, 35(16), 2025-2033.

Brenzel, L., Young, D., \& Walker, D. G. (2015). Costs and financing of routine immunization: approach and selected findings of a multi-country study (EPIC). Vaccine, 33, A13-A20.

Carrasco, P., Franco-Paredes, C., Andrus, J., Waller, K., Maassen, A., Symenouh, E., \& Hafalia, G. (2015). Inaugural conference of the International Association of Immunization Managers (IAIM), Istanbul Turkey, 3-4 March 2015. Vaccine, 33(33), 4047-4050.

Ducusin, M. J. U., de Quiroz-Castro, M., Roesel, S., Garcia, L. C., Cecilio-Elfa, D., Schluter, W. W., . . . Lam, E. (2017). Using the World Health Organization measles programmatic risk assessment tool for monitoring of supplemental immunization activities in the Philippines. Risk Analysis, 37(6), 1082-1095.

Eboreime, E., Abimbola, S., \& Bozzani, F. (2015). Access to routine immunization: a comparative analysis of supply-side disparities between northern and southern Nigeria. PloS one, 10(12), e0144876.

Faneye, A. O., Adeniji, J. A., Olusola, B. A., Motayo, B. O., \& Akintunde, G. B. (2015). Measles virus infection among vaccinated and unvaccinated children in Nigeria. Viral immunology, 28(6), 304-308.

Fowotade, A., Okonko, I., Nwabuisi, C., Bakare, R., Fadeyi, A., \& Adu, F. (2015). Measles vaccine potency and sero-conversion rates among infants receiving measles immunization in Ilorin, Kwara State, Nigeria. Journal of Immunoassay and Immunochemistry, 36(2), 195209.

Gibson, D. G., Ochieng, B., Kagucia, E. W., Obor, D., Odhiambo, F., O’Brien, K. L., \& Feikin, D. R. (2015). Individual level determinants for not receiving immunization, receiving immunization with delay, and being severely underimmunized among rural western Kenyan children. Vaccine, 33(48), 6778-6785.

Gunnala, R., Ogbuanu, I. U., Adegoke, O. J., Scobie, H. M., Uba, B. V., Wannemuehler, K. A., ... Mustafa, M. (2016). Routine vaccination coverage in Northern Nigeria: results from 40 district-level cluster surveys, 2014-2015. PloS one, 11(12), e0167835.

Habib, M. A., Soofi, S. B., Ali, N., Hussain, I., Tabassum, F., Suhag, Z., . . Bhutta, Z. A. (2017). Knowledge and perceptions of polio and polio immunization in polio high-risk areas of Pakistan. Journal of public health policy, 38(1), 16-36.

Healy, C. M., Rench, M. A., Montesinos, D. P., Ng, N., \& Swaim, L. S. (2015). Knowledge and attitiudes of pregnant women and their providers towards recommendations for immunization during pregnancy. Vaccine, 33(41), 5445-5451. 
Idi, B. (2017). Spatio-temporal mapping of solar energy potential of Dutse, Jigawa State Nigeria using arcgis solar radiation spatial analyst tool. Bayero Journal of Pure and Applied Sciences, 10(1), 596-600.

Iduseri, A., \& Osemwenkhae, J. (2016). On Maintaining High Levels of Immunization Coverage in Edo State Using Binary Logistic Regression Model. Journal of the Nigerian Association of Mathematical Physics, 35, 201-208.

Liso, A., Massenzio, F., \& Stracci, F. (2017). PLAC1 immunization does not induce infertility in mice. Immunotherapy, 9(6), 481-486.

Mpabalwani, E. M., Mwenda, J. M., Tate, J. E., \& Parashar, U. D. (2017). Review of naturally occurring intussusception in young children in the WHO African region prior to the era of rotavirus vaccine utilization in the expanded programme of immunization. Journal of tropical pediatrics, 63(3), 221-228.

Muloiwa, R., Kagina, B. M., Engel, M. E., \& Hussey, G. D. (2015). The burden of pertussis in lowand middle-income countries since the inception of the Expanded Programme on Immunization (EPI) in 1974: a systematic review protocol. Systematic reviews, 4(1), 62.

Nakayiza, M. F. (2018). Factors Associated With Uptake Of Dpt 3 Immunization Amongst Children Aged 6-12 Months In Kawempe-MBOGO Village, Kawempe Division, Kampala District. International Health Sciences University.

Omer, S. B. (2017). Maternal immunization. New England Journal of Medicine, 376(13), 12561267.

Ongwae, K. M., Bawa, S. B., Shuaib, F., Braka, F., Corkum, M., \& Isa, H. K. (2017). Use of Dedicated mobile teams and polio volunteer community mobilizers to increase access to zero-dose oral poliovirus vaccine and routine childhood immunizations in settlements at high risk for polio transmission in northern Nigeria. The Journal of infectious diseases, 216(suppl_1), S267-S272.

Paul, S., \& Sahoo, J. (2015). Four new vaccines for routine immunization in India: What about hemophilus influenza B and pneumococcal vaccine? Journal of family medicine and primary care, 4(1), 9.

Petrosky, E., Bocchini Jr, J. A., Hariri, S., Chesson, H., Curtis, C. R., Saraiya, M., . . Markowitz, L. E. (2015). Use of 9-valent human papillomavirus (HPV) vaccine: updated HPV vaccination recommendations of the advisory committee on immunization practices. MMWR. Morbidity and mortality weekly report, 64(11), 300.

Roca, A., Bojang, A., Bottomley, C., Gladstone, R. A., Adetifa, J. U., Egere, U., . . Kampmann, B. (2015). Effect on nasopharyngeal pneumococcal carriage of replacing PCV7 with PCV13 in the Expanded Program of Immunization in The Gambia. Vaccine, 33(51), 7144-7151.

Saleh, J.-E. A. (2016). Trends of measles in Nigeria: A systematic review. Sahel Medical Journal, 19(1), 5.

Touray, K., Mkanda, P., Tegegn, S. G., Nsubuga, P., Erbeto, T. B., Banda, R., . . Vaz, R. G. (2016). Tracking vaccination teams during polio campaigns in Northern Nigeria by use of geographic information system technology: 2013-2015. The Journal of infectious diseases, 213(suppl_3), S67-S72.

Verguet, S., Johri, M., Morris, S. K., Gauvreau, C. L., Jha, P., \& Jit, M. (2015). Controlling measles using supplemental immunization activities: a mathematical model to inform optimal policy. Vaccine, 33(10), 1291-1296. 
INTERNATIONAL JOURNAL OF ACADEMIC RESEARCH ECONOMICS AND MANAGEMENT SCIENCES Vol. 9, No. 1, 2019, E-ISSN: 2226-3624 @ 2019 HRMARS

Yahaya, R., \& Dogara, M. (2018). Prevalence of Cryptosporidium species and Giardia intestinalis among patients in a secondary health facility, Dutse, Jigawa State, Nigeria. Nigerian Journal of Parasitology, 39(1), 84-90. 